\title{
LATERAL BENDING OF SYMMETRICALLY LOADED CONICAL DISCS*
}

\author{
BY \\ K. E. BISSHOPP \\ Fairbanks, Morse \& Company, Beloit, Wisconsin**
}

1. Introduction. The general theory of lateral bending for thin circular plates of variable thickness is given in Timoshenko's book, "Theory of plates and shells," where also may be found numerous references to the literature of the subject. Of particular interest is a reference to Föppl who indicated the analogy existing between the rotating disc problem and that of lateral bending in a circular plate of variable thickness. Comparison of the solution for the rotating conical disc problem with the corresponding one for lateral bending shows that the basic differential equations involved, and the expressions for the stresses, are analogous. Therefore, previously described methods ${ }^{2}$ for obtaining solutions of the former problem in terms of hypergeometric functions are applicable to the latter problem. It will appear later that the special type of hypergeometric differential equation associated with the lateral bending problem has solutions which give the stress coefficients with less labor than in the case of the rotating conical disc.

The stress coefficients have been arranged conveniently for numerical calculation of conical discs, which are component parts of a wide variety of engineering structures. The head of a large poppet valve provides a particular example where the principal stress member can be approximated by a system of incomplete conical discs. In order to illustrate an application of the theory, stress coefficients for conical discs subject to lateral bending as well as for rotating conical discs will be used to estimate stress distributions in a steel valve head of constant weight and various proportions. Since the coefficients are obtained from solutions of differential equations for thin discs, the approximate method breaks down in the neighborhood of the valve stem. These limitations have little effect near the periphery, which makes it possible to calculate valve proportions corresponding to approximately uniform stress distribution throughout the head. The description of the illustrative example at the end of the paper explains the method of calculation in detail.

2. Derivation of differential equation. Let $M_{r}$ and $M_{t}$ denote radial and tangential bending moments per unit length acting on an element of a circular plate at distance $r$ from the center; then if $Q$ is the corresponding circumferential shearing force per unit length, the equation of equilibrium is

$$
M_{r}+r d M_{r} / d r-M_{t}=-Q_{r} \text {. }
$$

If $w$ denotes downward deflection of the middle surface, then

* Received Jan. 29, 1944.

** Now at Armour Research Foundation, Chicago, Ill.

1 Timoshenko, Theory of plates and shells, McGraw-Hill, 1st Edition 1940, Art. 54, p. 282.

$2 \mathrm{~K}$. E. Bisshopp, Stress coefficients for rotating discs of conical profile, Journal of Applied Mechanics, Vol. 11, No. 1, March 1944, pp. A1-A9. 


$$
\begin{aligned}
& M_{r}=-D\left(\frac{d^{2} w}{d r^{2}}+\frac{\sigma}{r} \frac{d w}{d r}\right)=D\left(\frac{d \varphi}{d r}+\frac{\sigma}{r} \varphi\right), \\
& M_{t}=-D\left(\frac{1}{r} \frac{d w}{d r}+\sigma \frac{d^{2} w}{d r^{2}}\right)=D\left(\frac{\varphi}{r}+\sigma \frac{d \varphi}{d r}\right),
\end{aligned}
$$

where $\sigma$ is Poisson's ratio, $\varphi=-d w / d r$ and $D=E h^{3} / 12\left(1-\sigma^{2}\right), E$ being Young's modulus and $h$ the thickness of the plate; $D$ is called the flexural rigidity.

In the case of a conical profile, $h$ is a linear function of $r$, so that substitution from Eqs. (2) in Eq. (1) gives

$$
D \frac{d}{d r}\left(\frac{d \varphi}{d r}+\frac{\varphi}{r}\right)+\frac{d D}{d r}\left(\frac{d \varphi}{d r}+\sigma \frac{\varphi}{r}\right)=-Q .
$$

In order to reduce this equation to non-dimensional form, we introduce the radius $R$ to the knife edge of the disc and the thickness $h_{0}$ at the center. If $r / R=x$, then $h=h_{0}(1-x)$, and Eq. (3) becomes

$$
\frac{d^{2} \varphi}{d x^{2}}+\left(\frac{1}{x}-\frac{3}{1-x}\right) \frac{d \varphi}{d x}-\left(\frac{1}{x^{2}}+\frac{3 \sigma}{x(1-x)}\right) \varphi=-\frac{12 Q R^{2}\left(1-\sigma^{2}\right)}{E h_{0}^{3}(1-x)^{3}} .
$$

For any particular type of symmetrical loading the shearing force $Q$ is a function of $x$ alone. The maximum radial and tangential bending stresses $S_{r}$ and $S_{t}$ are obtained from the general solution of Eq. (4) with the aid of Eqs. (2) and the relations

$$
S_{r}=6 M_{r} / h^{2}, \quad S_{t}=6 M_{t} / h^{2} .
$$

The problem of a conical disc supporting a concentrated vertical load $P$ at the center has some interesting practical applications. In this case $Q=P / 2 \pi r=P / 2 \pi R x$, and Eq. (4) becomes

$$
x(1-x) \frac{d^{2} \varphi}{d x^{2}}+(1-4 x) \frac{d \varphi}{d x}-\left(\frac{1-x}{x}+3 \sigma\right) \varphi=-\frac{6 P R\left(1-\sigma^{2}\right)}{\pi E h_{0}^{2}(1-x)^{2}} .
$$

It can be verified by substitution that a particular integral of Eq. (5) is

$$
\varphi_{3}(x)=-\frac{2 P R(1+\sigma)}{\pi E h_{0}^{3}(1-3 \sigma)}\left(\frac{2-3 \sigma}{(1-x)^{2}}+\frac{1}{x}+\frac{1}{1-x}\right) .
$$

The auxiliary equation, the solutions of which are independent of the type of loading, is obtained by setting the right hand side of Eq. (5) equal to zero. After making the substitution $\varphi=x F$, we obtain

$$
x(1-x) \frac{d^{2} F}{d x^{2}}+3(1-2 x) \frac{d F}{d x}-3(1+\sigma) F=0,
$$

which is recognized to be of hypergeometric type.

3. Complementary functions. Equation (7) is of the form

$$
x(1-x) \frac{d^{2} F}{d x^{2}}+[c-(a+b+1) x] \frac{d F}{d x}-a b F=0,
$$


where $c=3, a+b=5$, and $a b=3(1+\sigma)$. 'The first solution can be represented by a power series; the integral exponent difference ${ }^{3} 1-c=-2$ shows that the second solution contains a logarithm. ${ }^{*}$ In the notation of the hypergeometric function, the first solution is

$$
F_{1}(x)=F(a, b, c, x)=1+\frac{a b}{1 \cdot c} x+\frac{a(a+1) b(b+1)}{1 \cdot 2 \cdot c(c+1)} x^{2}+\cdots,
$$

which converges absolutely and uniformly when $|x|<1$. The asymptotic behavior of the hypergeometric function in the neigborhood of its poles is given by ${ }^{4}$

$$
F(a, b, c, x) \sim \frac{\Gamma(c) \Gamma(a+b-c)}{\Gamma(a) \Gamma(b)}(1-x)^{c-a-b},
$$

whenever $c-a-b$ is an integer less than zero, $\Gamma(z)$ being the well known gamma function. Thus $F_{1}(x)$ has a second order singularity at $x=1$ such that,

$$
F_{x \rightarrow 1}(x) \sim \frac{\Gamma(3) \Gamma(2)}{\Gamma(a) \Gamma(b)}(1-x)^{-2}=\frac{2(1-x)^{-2} \sin a \pi}{\pi(a-1)(a-2)(a-3)(a-4)},
$$

which may be used to approximate the function for values of $x$ near unity. The presence of singularities of lower order in the remainder term for $F_{1}(x)$ makes this method unsuitable for accurate numerical work. Better approximations for similar functions with second and third order singularities are given in Ref. (2).

The logarithmic solution ${ }^{5}$ of Eq. (7) is $\dagger$

$$
F_{2}(x)=-\frac{(a b-4)(a b-6)}{2} F_{1}(x) \log _{a} x+\frac{1}{x^{2}}-\frac{a b-6}{x}-g(x),
$$

where

$$
g(x)=\sum_{n=2}^{\infty} \frac{(n+a-3) \cdots(a-2)(n+b-3) \cdots(b-2)}{n !(n-2) !} x^{n-2} \Phi_{n},
$$

and

$$
\begin{aligned}
\Phi_{n}= & \psi(n-3+a)+\psi(n-3+b)-\psi(n)-\psi(n-2) \\
= & \frac{1}{a-2}+\cdots+\frac{1}{a+n-3}+\frac{1}{b-2}+\cdots+\frac{1}{b+n-3} \\
& -1-\frac{1}{2}-\cdots-\frac{1}{n}-1-\frac{1}{2}-\cdots-\frac{1}{n-2} .
\end{aligned}
$$

The principal part of expansion (11) shows that $F_{2}(x)$ has a second order singularity at the origin. The nature of the singularity at $x=1$ can be recognized by observing p. 198.

${ }^{3}$ Whittaker and Watson, $A$ course of modern analysis, Cambridge, England, 4th Edition, 1927,

* When $\sigma=1 / 3$ both solutions can be expressed in terms of rational algebraic functions.

4 Titchmarsh, Theory of functions, Oxford, England, 1932, p. 224.

' Forsyth, Theory of differential equations, Cambridge, England, 1902, vol. 4, part 3, p. 147.

$\dagger$ The numerical value of $c$ is used since it is independent of Poisson's ratio $\sigma$. 
the limiting form of the $n$th term of $g(x)$ which is proportional to that of $F_{1}(x)$ provided $\lim _{n \rightarrow \infty} \Phi_{n}$ remains finite. That this is the case can be shown with the aid of the logarithmic derivative ${ }^{6}$ of the Gamma function, which gives

$$
\lim _{n \rightarrow \infty} \Phi_{n}=2\left(\frac{1}{a-2}+\frac{1}{a-1}+\frac{1}{a}\right)-2 \gamma-2 \Psi(a)-\pi \cot a \pi,
$$

where $\Psi(a)=\Gamma^{\prime}(a+1) / \Gamma(a+1)$ and $\gamma$ is Euler's constant. Thus $F_{2}(x)$ has a second order singularity at $x=1$ of magnitude

$$
\underset{x \rightarrow 1}{F_{2}(x)} \sim-\lim _{n \rightarrow \infty} \Phi_{n} \frac{\sin a \pi}{\pi} /(1-x)^{2} .
$$

The slow convergence of the power series near the singularities of $F_{1}(x)$ and $F_{2}(x)$ makes numerical evaluation of the stress coefficients for all values of $x$ between zero and unity exceedingly difficult, in spite of available asymptotic approximations. One scheme for removing this difficulty would be to construct from the transformed differential equation (7) two new solutions of argument $1-x$ and combine them linearly with $F_{1}(x)$ and $F_{2}(x)$, as described in Ref. (2). This differential equation is invariant under transformation by $1-x$, which brings about added convenience of calculation; however, considerable further reduction in computation can be accomplished by expressing $F_{1}(x)$ and $F_{2}(x)$ in terms of symmetrical hypergeometric functions.

4. Solutions in terms of even and odd functions. Whenever $2 c=a+b+1$, which condition is satisfied by Eq. (7), the transformation $(1-2 x)^{2}=t$ reduces the standard form of the hypergeometric equation to

$$
t(1-t) \frac{d^{2} F}{d t^{2}}+\left[\frac{1}{2}-\left(\frac{a}{2}+\frac{b}{2}+1\right) t\right] \frac{d F}{d t}-\frac{a b}{4} F=0 .
$$

The solutions of this equation as functions of $x$ are

$F\left\{\frac{1}{2} a, \frac{1}{2} b, \frac{1}{2},(1-2 x)^{2}\right\} \equiv G_{1}(x),(1-2 x) F\left\{\frac{1}{2}(a+1), \frac{1}{2}(b+1), \frac{3}{2},(1-2 x)^{2}\right\} \equiv G_{2}(x)$.

This shows that $G_{1}(x)=G_{1}(1-x)$ and $G_{2}(x)=-G_{2}(1-x)$. Since only functions of $x$ are involved,

$$
\begin{aligned}
& G_{1}(x)=C_{1} F_{1}(x)+C_{2} F_{2}(x), \\
& G_{2}(x)=D_{1} F_{1}(x)+D_{2} F_{2}(x),
\end{aligned}
$$

where $C_{1}, C_{2}, D_{1}, D_{2}$ are constants; $G_{1}(x)$ and $G_{2}(x)$ are respectively even and odd relative to the point $x=\frac{1}{2}$. The series for $G_{1}(x)$ and $G_{2}(x)$ are very convenient for computation when $.25 \leqq x \leqq .50$, while those for $F_{1}(x)$ and $F_{2}(x)$ are equally so when $0 \leqq x \leqq .25$. Since the $G$ 's are symmetrical it is necessary to compute only one half as many fundamental values for constructing tables of stress coefficients as would be required with the $F$ 's. From this point on therefore, the $F$ 's are subordinated to the role of "helping functions," while the $G$ 's form the basis of all subsequent calculations.

Returning to Eq. (17), we employ the familiar method of comparison of singularities for evaluation of the linear factors. It is apparent from the character of the $F$ 's that the $G$ 's have second order singularities at zero and unity whose values may be deduced from Eq. (9). After some reduction, we obtain

- Ref. 3, p. 246.

' Ref. 3, p. 297, Example 7. 


$$
\begin{aligned}
& C_{1}=\frac{\sqrt{\pi} \Gamma(a) \Gamma(b)}{32 \Gamma\left(\frac{1}{2} a\right) \Gamma\left(\frac{1}{2} b\right)}\left[1+\lim _{n \rightarrow \infty} \Phi_{n} \frac{\sin a \pi}{\pi}\right], \\
& C_{2}=\sqrt{\pi} /\left[16 \Gamma\left(\frac{1}{2} a\right) \Gamma\left(\frac{1}{2} b\right)\right], \\
& D_{1}=-\frac{\sqrt{\pi} \Gamma(a) \Gamma(b)}{64 \Gamma\left\{\frac{1}{2}(a+1)\right\} \Gamma\left\{\frac{1}{2}(b+1)\right\}}\left[1-\lim _{n \rightarrow \infty} \Phi_{n} \frac{\sin a \pi}{\pi}\right], \\
& \dot{D}_{2}=\sqrt{\pi} /\left[32 \Gamma\left\{\frac{1}{2}(a+1)\right\} \Gamma\left\{\frac{1}{2}(b+1)\right\}\right] .
\end{aligned}
$$

The functions $G_{1}(x), G_{2}(x)$, and their derivatives are tabulated in Table 1.

Since the $F$ 's and $G$ 's are linearly dependent, $x G_{1}(x)$ and $x G_{2}(x)$ are fundamental solutions of Eq. (5), from which, by use of Eqs. (2) and (4a), the stress coefficients follow immediately.

5. Determination of the deflection functions. The deflection $w(x)$ can be expressed in the form

$$
w(x)=R\left[w_{1}(x)+w_{2}(x)+\bar{w}_{3}(x)\right],
$$

where $w_{1}(x)$ and $w_{2}(x)$ arise from the complementary functions respectively, and $\bar{w}_{3}(x)$ arises from the particular integral. The calculation of $\bar{w}_{3}(x)$ presents no difficulty, since only elementary functions with known integrals are involved. Direct in tegration of Eq. (6) gives

$$
\bar{w}_{3}(x)=-\int \varphi_{3}(x) d x=\frac{2 P R(1+\sigma)}{\pi E h_{0}^{3}(1-3 \sigma)}\left[\frac{2-3 \sigma}{1-x}+\log _{e} \frac{x}{1-x}\right] .
$$

The construction of the deflection functions $w_{1}(x)$ and $w_{2}(x)$ is considerably more difficult, since it is necessary to evaluate integrals of the type $\int x G_{i}(x) d x(i=1,2)$, which involves additional infinite series. For purposes of computation, a convenient procedure, that also has the advantage of being easy to check, is to use a combination of analytical and numerical methods. A prerequisite for this calculation is a fairly extensive and accurate tabulation of the $G$ 's.

A straightforward step by step numerical integration process is seen to fail near the poles of the $G$ 's, due to the presence of ordinary singularities in the integrands. The procedure for constructing the functions $w_{1}(x)$ and $w_{2}(x)$ in tabular form consists of removing these singularities analytically and integrating the resulting functions numerically.

6. Removal of singularities from the integrands of $\int x G_{1}(x) d x$ and $\int x G_{2}(x) d x$. Let us consider a "substracting off" function $H_{1}(x)$ which has the property that $G_{1}(x)-H_{1}(x)$ is bounded uniformly, i.e., without finite jumps, throughout the interval of existence of $G_{1}(x)$. It is necessary that $H_{1}(x)$ be continuous except for poles which are of the same order as, and coincide with, those of $G_{1}(x)$. This specification is not sufficient however, since at every point of the interval the difference $G_{1}(x)-H_{1}(x)$ is finite, which requires the principal parts of $G_{1}(x)$ and $H_{1}(x)$ to be identical. The principal parts of $G_{1}(x)$ at zero and unity are readily obtainable from Eqs. (11) and (17) together with the relation $G_{1}(x)=G_{1}(1-x)$. Since $G_{2}(x)$ $=-G_{2}(1-x)$ and the $F$ 's and $G$ 's are linearly dependent, the corresponding principal parts of $G_{2}(x)$ may be found by the same process. 
The integral parts of $G_{1}(x)$ and $G_{2}(x)$ can be approximated by polynomials of low degree, which makes it possible to reduce the differences $G_{1}(x)-H_{1}(x)$ and $G_{2}(x)-H_{2}(x)$ to uniformly small values throughout the interval by an intelligent choice of the "subtracting off" functions. Incidentally this process provides a convenient check on the accuracy of the tabulated values of the $G$ 's. After some manipulation a pair of suitable "subtracting off" functions were found to be

$$
\begin{aligned}
H_{1}(x)= & C_{2}\left[-7+a b-g(0)+C_{1} / C_{2}-\frac{1}{2}(a b-4)(a b-6) \log _{e} x(1-x)\right. \\
& \left.+1 / x^{2}+1 /(1-x)^{2}-(a b-6) / x-(a b-6) /(1-x)\right], \\
H_{2}(x)= & D_{2}\left[\left(7-a b-g(0)+D_{1} / D_{2}\right)(1-2 x)-\frac{1}{2}(a b-4)(a b-6) \log _{e}\{x /(1-x)\}\right. \\
& \left.+1 / x^{2}-1 /(1-x)^{2}-(a b-6) / x+(a b-6) /(1-x)\right] .
\end{aligned}
$$

These functions have the added property that

$$
\lim _{x \rightarrow 0, x \rightarrow 1}\left\{G_{1}(x)-H_{1}(x)\right\}=\lim _{x \rightarrow 0, x \rightarrow 1}\left\{G_{2}(x)-H_{2}(x)\right\}=0 .
$$

Integrals of the type $\int x G(x) d x$ now can be evaluated directly from the identity

$$
-w_{i}(x)=\int x G_{i}(x) d x \equiv \int x\left[G_{i}(x)-H_{i}(x)\right] d x+\int x H_{i}(x) d x, \quad(i=1,2) .
$$

The second integral on the right-hand side is expressible in terms of elementary functions, while the first one behaves like a polynomial which can be computed easily with any numerical integration formula having a suitably small remainder depending on the magnitude of the differences of $x\left[G_{i}(x)-H_{i}(x)\right]$. Evaluation of the second integral of Eq. (22) with $\sigma=.3$ gives, with the constant of integration chosen so that $w_{1}\left(\frac{1}{2}\right)=w_{2}\left(\frac{1}{2}\right)=0$,

$$
\begin{gathered}
\int x H_{1}(x) d x=.060,042,74\left\{.082,589,7 x^{2}+.052,500,0 x-2.103,471\right. \\
\left.+\frac{1}{1-x}+\log _{\odot} x-1.047,500,0 \log _{\odot}(1-x)-.052,500,0 x^{2} \log _{\odot} x(1-x)\right\}, \\
\int x H_{2}(x) d x=.040,784,50\left\{.080,308,8 x^{3}-.060,231,6 x^{2}+4.147,500 x+1.349,471,6\right. \\
\left.\quad-\frac{1}{1-x}+\log _{\odot} x+1.0475,000,0 \log _{\odot}(1-x)+.052,500,0 x^{2} \log _{\bullet} \frac{1-x}{x}\right\} .
\end{gathered}
$$

7. Deflection and stress coefficients. It is convenient to state the actual deflection in the form

$$
w=\frac{2 R^{2}\left(1-\sigma^{2}\right)}{E h_{0}}\left[A w_{1}+B w_{2}+\left(P / h_{0}^{2}\right) w_{3}+C\right],
$$

where, from Eqs. (18a) and (19),

$$
w_{3}=\frac{1}{\pi(1-3 \sigma)(1-\sigma)}\left[\frac{2-3 \sigma}{1-x}+\log _{e} \frac{x}{1-x}\right],
$$

and $w_{1}$ and $w_{2}$ are non-dimensional functions of $x$ defined by Eq. (22). $w_{1}, w_{2}, w_{3}$ 
are deflection coefficients, and are tabulated in Table 2. The constants $A, B$, and $C$ are seen to have the dimensions of stress.

The bending stresses can be stated in a form entirely analogous to that obtained for the rotating disc problem. With the aid of Eqs. (4a), (2), and (25), we have

$$
\begin{aligned}
& S_{r}=A p_{1}+B p_{2}+\left(P / h_{0}^{2}\right) p_{3}, \\
& S_{t}=A q_{1}+B q_{2}+\left(P / h_{0}^{2}\right) q_{3},
\end{aligned}
$$

where

$$
\begin{aligned}
& p_{1}=(1-x)\left[x d G_{1} / d x+(1+\sigma) G_{1}\right], \\
& q_{1}=(1-x)\left[\sigma x d G_{1} / d x+(1+\sigma) G_{1}\right] ;
\end{aligned}
$$

a similar pair of relations apply to $p_{2}$ and $q_{2}$; when $\sigma=.3, p_{3}$ and $q_{3}$ can be computed directly from the formulas

$$
\begin{aligned}
& p_{3}=-4.547284 \frac{1-x}{x}\left[\frac{.63+2.27 x-.7 x^{2}}{(1-x)^{3}}-\frac{.7}{x}\right], \\
& q_{3}=-4.547284 \frac{1-x}{x}\left[\frac{2.1-2.14 x+.7 x^{2}}{(1-x)^{3}}+\frac{.7}{x}\right] .
\end{aligned}
$$

$p_{1}, p_{2}, p_{3}, q_{1}, q_{2}, q_{3}$ are the stress coefficients, and are tabulated in Tables 3 and 4 .

The tables of coefficients are especially convenient for approximating a plate of variable thickness with a system of conical profiles. Calculations in this type of problem show that it is necessary that the coefficients be accurate to six significant figures in order to obtain four significant figures in the final results. Consequently the tables have been calculated accurately to five parts in two million. Their general usefulness can be extended considerably. with the aid of an auxiliary table of interpolation coefficients. It was found that such a table based on Bessel's central difference formula ${ }^{8}$ for six ordinates gives interpolated values of the coefficients as accurately as the tabulated ones, except near the ends of the table where the values are seldom used. In such cases a knowledge of the singularities of the tabulated functions indicates the necessary procedure for applying an interpolation formula.

\section{Illustrative Example}

Stress distributions in a steel valve of constant weight and various proportions were estimated by an approximate method based on thin conical disc stress coeffcients tabulated for both the lateral bending and rotating cases. The valve head is represented by a system of truncated conical shells of variable thickness, whose apex angles are nearly $180^{\circ}$ as shown in Fig. 1 . The angle of the seat determines the direction of the reaction which imposes two independent stress systems on the valve head. An approximation to these stresses can be made on the assumption that the membrane and bending stresses correspond to those in an equivalent system of conical discs. This assumption is admissible, since it has been demonstrated ${ }^{9}$ for conical shells of constant thickness, that the stress distribution has the same character as that in a

${ }^{8} \mathrm{~J}$. B. Scarborough, Numerical mathematical analysis, The Johns Hopkins Press, Baltimore, Md., 1930, p. 64.

Ref. 1, p. 477. 
circular plate whenever the apex angle of the shell is between $168^{\circ}$ and $180^{\circ}$. The loads on the composite disc shown in Fig. 2 are determined by resolving the valve seat reaction (of which the axial force is a component) into two perpendicular components, one of which produces pure compression on a section normal to the middle

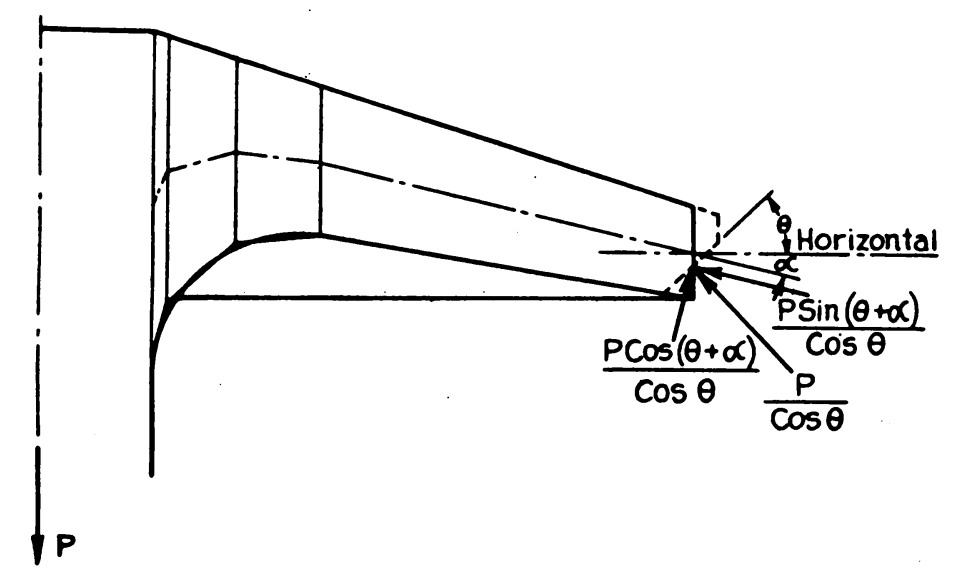

Fig. 1. Half section of valve.

surface at the periphery, and the other of which produces pure bending. ${ }^{*}$ The peripheral forces per unit length are proportional to the resultant vertical force acting on the valve, so that the force resolution in Figs. 1 and 2 has been made in terms of the axial force $P$, which is considered as a concentrated load, such as would

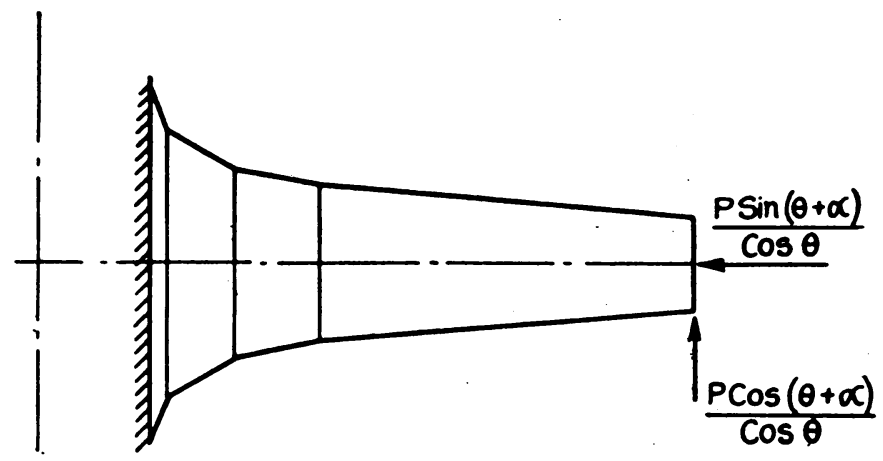

FIG. 2. Half section of composite disc.

be imposed on the valve by impact against its seat. It is safe to assume a concentrated axial load since the impact forces are proportional to the total valve weight, of which approximately $50 \%$ is in the stem.

The next step in the calculation is to represent the valve head by a system of equivalent conical discs in the usual manner. The tabular solution for the bending stresses is obtained from the calculation procedure described in Ref. (2), except that

* Variation in the slopes of corresponding generators of middle surfaces belonging to the conical discs of the equivalent system is not considered. 
the $p$ 's and $q$ 's now refer to lateral bending coefficients and $\rho R_{n}^{2} \omega^{2}$ is replaced by $P / h_{n 0}^{2}$. The solution for the membrane stresses is unchanged with the exception that the coefficients of $p_{3}$ and $q_{3}$ are zero, which corresponds to a static stress distribution

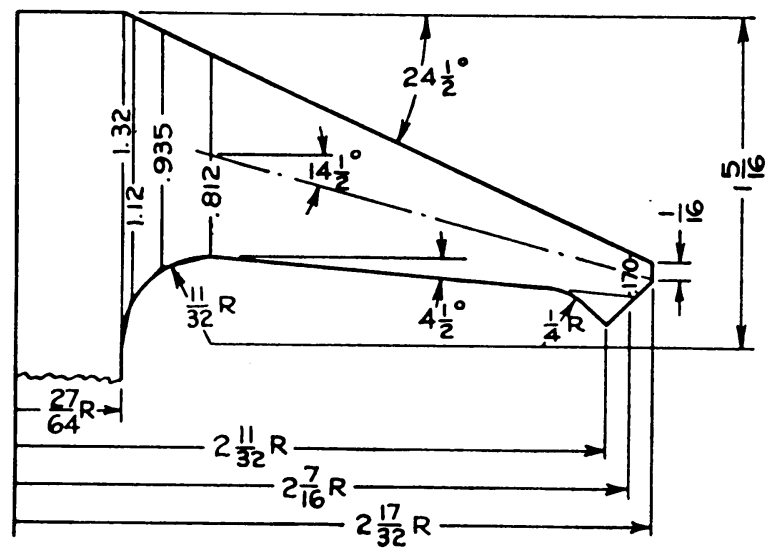

Fig. 3.

in a rotating disc. If $\bar{S}_{r}$ and $\bar{S}_{t}$ refer to the corresponding membrane stresses respectively, then the appropriate boundary conditions are: at the boundary between valve stem and head, $S_{t}=\sigma S_{r}, \bar{S}_{t}=\bar{S}_{r}$; at the periphery $S_{r}=0, \bar{S}_{r}$ assigned.

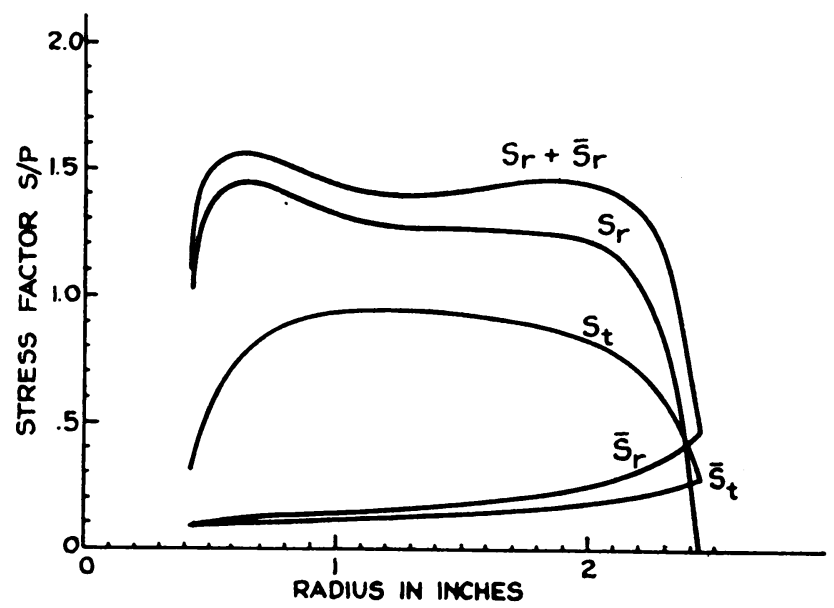

Fig. 4.

The dimensions of the valve head and the results of the stress calculations are shown in Figs. 3 and 4 respectively. 
TABLE 1.*-Fundamental solutions of hypergeometric equation, $\sigma=.30$.

\begin{tabular}{|c|c|c|c|c|}
\hline$x$ & $G_{1}(x)=G_{1}(1-x)$ & $G_{1}^{\prime}(x)=-G_{1}^{\prime}(1-x)$ & $G_{2}(x)=-G_{2}(1-x)$ & $G_{2}^{\prime}(x)=G_{2}^{\prime}(1-x)$ \\
\hline $\begin{array}{l}.00 \\
.01 \\
.02 \\
.03 \\
.04\end{array}$ & $\begin{array}{c}{ }^{\infty} \\
613.258 \\
156.631,5 \\
71.137,6 \\
40.900,5\end{array}$ & $\begin{array}{c}-\infty \\
-121,346.7 \\
-15,325.94 \\
-4,587.63 \\
-1,955.005\end{array}$ & $\begin{array}{c}\infty \\
416.297 \\
106.126,0 \\
48.050,0 \\
27.507,5\end{array}$ & $\begin{array}{c}-\infty \\
-82,426.1 \\
-10,410.62 \\
-3,116.55 \\
-1,328.327\end{array}$ \\
\hline $\begin{array}{l}.05 \\
.06 \\
.07 \\
.08 \\
.09\end{array}$ & $\begin{array}{l}26.762,0 \\
19.005,02 \\
14.282,02 \\
11.187,24 \\
9.045,62\end{array}$ & $\begin{array}{r}-1,010.946 \\
-590.775 \\
-375.613 \\
-254.002 \\
-180.034,7\end{array}$ & $\begin{array}{r}17.900,04 \\
12.627,16 \\
9.415,02 \\
7.308,76 \\
5.849,83\end{array}$ & $\begin{array}{l}-687.077 \\
-401.683 \\
-255.543 \\
-172.948,9 \\
-122.717,7\end{array}$ \\
\hline $\begin{array}{l}.10 \\
.11 \\
.12 \\
.13 \\
.14\end{array}$ & $\begin{array}{l}7.499,77 \\
6.345,89 \\
5.460,74 \\
4.766,18 \\
4.210,70\end{array}$ & $\begin{array}{r}-132.421,0 \\
-100.354,8 \\
-77.948,5 \\
-61.804,5 \\
-49.867,4\end{array}$ & $\begin{array}{l}4.795,46 \\
4.007,22 \\
3.401,39 \\
2.924,89 \\
2.542,72\end{array}$ & $\begin{array}{l}-90.387,7 \\
-68.619,0 \\
-53.412,3 \\
-42.459,9 \\
-34.365,6\end{array}$ \\
\hline $\begin{array}{l}.15 \\
.16 \\
.17 \\
.18 \\
.19\end{array}$ & $\begin{array}{l}3.759,18 \\
3.386,98 \\
3.076,44 \\
2.814,56 \\
2.591,67\end{array}$ & $\begin{array}{l}-40.842,7 \\
-33.887,3 \\
-28.435,8 \\
-24.098,7 \\
-20.602,3\end{array}$ & $\begin{array}{l}2.231,01 \\
1.973,046 \\
1.756,797 \\
1.573,446 \\
1.416,397\end{array}$ & $\begin{array}{l}-28.250,3 \\
-23.541,2 \\
-19.854,16 \\
-16.924,95 \\
-14.567,50\end{array}$ \\
\hline $\begin{array}{l}.20 \\
.21 \\
.22 \\
.23 \\
.24\end{array}$ & $\begin{array}{l}2.400,38 \\
2.235,01 \\
2.091,12 \\
1.965,196 \\
1.854,433\end{array}$ & $\begin{array}{l}-17.749,86 \\
-15.397,53 \\
-13.438,55 \\
-11.792,44 \\
-10.397,74\end{array}$ & $\begin{array}{r}1.280,639 \\
1.162,300 \\
1.058,356 \\
.966,410 \\
.884,547\end{array}$ & $\begin{array}{r}-12.648,25 \\
-11.069,57 \\
-9.758,98 \\
-8.661,87 \\
-7.736,55\end{array}$ \\
\hline $\begin{array}{l}.25 \\
.26 \\
.27 \\
.28 \\
.29\end{array}$ & $\begin{array}{l}1.756,562 \\
1.669,738 \\
1.592,445 \\
1.523,429 \\
1.461,645\end{array}$ & $\begin{array}{l}-9.206,96 \\
-8.182,97 \\
-7.296,48 \\
-6.524,11 \\
-5.847,10\end{array}$ & $\begin{array}{l}.811,215 \\
.745,149 \\
.685,309 \\
.630,829 \\
.580,987\end{array}$ & $\begin{array}{l}-6.950,83 \\
-6.279,56 \\
-5.702,90 \\
-5.205,08 \\
-4.773,43\end{array}$ \\
\hline $\begin{array}{l}.30 \\
.31 \\
.32 \\
.33 \\
.34\end{array}$ & $\begin{array}{l}1.406,220 \\
1.356,416 \\
1.311,608 \\
1.271,267 \\
1.234,939\end{array}$ & $\begin{array}{l}-5.250,21 \\
-4.721,02 \\
-4.249,27 \\
-3.826,49 \\
-3.445,58\end{array}$ & $\begin{array}{l}.535,174 \\
.492,874 \\
.453,647 \\
.417,115 \\
.382,950\end{array}$ & $\begin{array}{l}-4.397,71 \\
-4.069,55 \\
-3.782,13 \\
-3.529,80 \\
-3.307,88\end{array}$ \\
\hline $\begin{array}{l}.35 \\
.36 \\
.37 \\
.38 \\
.39\end{array}$ & $\begin{array}{l}1.202,236 \\
1.172,824 \\
1.146,417 \\
1.122,767 \\
1.101,661\end{array}$ & $\begin{array}{l}-3.100,60 \\
-2.786,52 \\
-2.499,05 \\
-2.234,53 \\
-1.989,781\end{array}$ & $\begin{array}{l}.350,869 \\
.320,623 \\
.291,994 \\
.264,788 \\
.238,834\end{array}$ & $\begin{array}{l}-3.112,48 \\
-2.940,33 \\
-2.788,70 \\
-2.655,29 \\
-2.538,15\end{array}$ \\
\hline $\begin{array}{l}.40 \\
.41 \\
.42 \\
.43 \\
.44\end{array}$ & $\begin{array}{l}1.082,915 \\
1.066,371 \\
1.051,893 \\
1.039,367 \\
1.028,695\end{array}$ & $\begin{array}{r}-1.762,067 \\
-1.548,980 \\
-1.348,397 \\
-1.158,434 \\
-.977,394\end{array}$ & $\begin{array}{l}.213,976 \\
.190,076,6 \\
.167,007,9 \\
.144,654,6 \\
.122,909,6\end{array}$ & $\begin{array}{l}-2.435,65 \\
-2.346,40 \\
-2.269,25 \\
-2.203,20 \\
-2.147,46\end{array}$ \\
\hline $\begin{array}{l}.45 \\
.46 \\
.47 \\
.48 \\
.49\end{array}$ & $\begin{array}{l}1.019,795 \\
1.012,600 \\
1.007,058 \\
1.003,128 \\
1.000,780\end{array}$ & $\begin{array}{l}-.803,742 \\
-.636,068 \\
-.473,063 \\
-.313,494 \\
-.156,186,3\end{array}$ & $\begin{array}{l}.101,673,3 \\
.080,852,4 \\
.060,358,2 \\
.040,105,8 \\
.020,013,2\end{array}$ & $\begin{array}{l}-2.101,34 \\
-2.064,31 \\
-2.035,94 \\
-2.015,90 \\
-2.003,96\end{array}$ \\
\hline .50 & $1.000,000$ & 0 & 0 & $-2.000,00$ \\
\hline
\end{tabular}

* The tables were compiled with the aid of the staff of the Calculation Department of Fairbanks Morse \& Co., Beloit, Wis., to whom acknowledgement hereby is made. 
ГАвLE 2.-Deflection coefficients for lateral bending of conical discs, $\sigma=.30$.

\begin{tabular}{|c|c|c|c|c|c|c|c|}
\hline$r / R$ & $w_{1}$ & $w_{2}$ & $w_{3}$ & $r / R$ & $w_{1}$ & $w_{2}$ & $w_{3}$ \\
\hline $\begin{array}{l}.00 \\
.01 \\
.02 \\
.03 \\
.04\end{array}$ & $\begin{array}{c}\infty \\
.341490 \\
.298578 \\
.272917 \\
.254305\end{array}$ & $\begin{array}{c}\infty \\
.1727156 \\
.1436068 \\
.1262435 \\
.1136970\end{array}$ & $\begin{array}{r}-\infty \\
-15.84278 \\
-12.59312 \\
-10.65009 \\
-9.24108\end{array}$ & $\begin{array}{l}.50 \\
.51 \\
.52 \\
.53 \\
.54\end{array}$ & \begin{tabular}{c|}
0 \\
-.00505132 \\
-.01021073 \\
-.01548680 \\
-.0208887
\end{tabular} & \begin{tabular}{|c|}
0 \\
.0000506834 \\
.000205606 \\
.000469405 \\
.000847188
\end{tabular} & $\begin{array}{l}10.00402 \\
10.39010 \\
10.78484 \\
11.18891 \\
11.60306\end{array}$ \\
\hline $\begin{array}{l}.05 \\
.06 \\
.07 \\
.08 \\
.09\end{array}$ & $\begin{array}{l}.239546 \\
.227215 \\
.216551 \\
.207102 \\
.1985728\end{array}$ & $\begin{array}{l}.1037962 \\
.0955742 \\
.0885157 \\
.0823131 \\
.0767682\end{array}$ & $\begin{array}{l}-8.12392 \\
-7.19072 \\
-6.38390 \\
-5.66908 \\
-5.02404\end{array}$ & $\begin{array}{l}.55 \\
.56 \\
.57 \\
.58 \\
.59\end{array}$ & $\begin{array}{l}-.0264263 \\
-.0321101 \\
-.0379516 \\
-.0439632 \\
-.0501582\end{array}$ & $\begin{array}{l}.001344576 \\
.001967757 \\
.00272355 \\
.00361945 \\
.00466373\end{array}$ & $\begin{array}{l}12.02809 \\
12.46484 \\
12.91425 \\
13.37730 \\
13.85508\end{array}$ \\
\hline $\begin{array}{l}.10 \\
.11 \\
.12 \\
.13 \\
.14\end{array}$ & $\begin{array}{l}.1907641 \\
.1835327 \\
.1767727 \\
.1704034 \\
.1643621\end{array}$ & $\begin{array}{l}.0717460 \\
.0671501 \\
.0629098 \\
.0589712 \\
.0552928\end{array}$ & $\begin{array}{l}-4.43361 \\
-3.88695 \\
-3.37604 \\
-2.89476 \\
-2.43835\end{array}$ & $\begin{array}{l}.60 \\
.61 \\
.62 \\
.63 \\
.64\end{array}$ & $\begin{array}{l}-.0565514 \\
-.0631588 \\
-.0699978 \\
-.0770879 \\
-.0844501\end{array}$ & $\begin{array}{l}.00586555 \\
.00723498 \\
.00878323 \\
.01052271 \\
.01246720\end{array}$ & $\begin{array}{l}14.34880 \\
14.85973 \\
15.38931 \\
15.93909 \\
16.51082\end{array}$ \\
\hline $\begin{array}{l}.15 \\
.16 \\
.17 \\
.18 \\
.19\end{array}$ & $\begin{array}{l}.1585986 \\
.1530724 \\
.1477501 \\
.1426040 \\
.1376105\end{array}$ & $\begin{array}{l}.0518418 \\
.0485919 \\
.0455217 \\
.0426135 \\
.0398528\end{array}$ & $\begin{array}{r}-2.00300 \\
-1.585657 \\
-1.183777 \\
-.795248 \\
-.418284\end{array}$ & $\begin{array}{l}.65 \\
.66 \\
.67 \\
.68 \\
.69\end{array}$ & $\begin{array}{l}-.0921083 \\
-.1000884 \\
-.1084197 \\
-.1171349 \\
-.1262706\end{array}$ & $\begin{array}{l}.01463208 \\
.01703454 \\
.01969381 \\
.0226315 \\
.0258720\end{array}$ & $\begin{array}{l}17.10641 \\
17.72799 \\
18.37793 \\
19.05890 \\
19.77389\end{array}$ \\
\hline $\begin{array}{l}.20 \\
.21 \\
.22 \\
.23 \\
.24\end{array}$ & $\begin{array}{l}.1327494 \\
.1280035 \\
.1233577 \\
.1187984 \\
.1143140\end{array}$ & $\begin{array}{l}.0372275 \\
.0347271 \\
.0323431 \\
.0300681 \\
.0278957\end{array}$ & $\begin{array}{r}-.0513587 \\
.306849 \\
.657492 \\
1.001586 \\
1.340034\end{array}$ & $\begin{array}{l}.70 \\
.71 \\
.72 \\
.73 \\
.74\end{array}$ & $\begin{array}{l}-.1358681 \\
-.1459743 \\
-.1566424 \\
-.1679333 \\
-.1799171\end{array}$ & $\begin{array}{l}.0294430 \\
.0333756 \\
.0377057 \\
.0424741 \\
.0477280\end{array}$ & $\begin{array}{l}20.5263 \\
21.3199 \\
22.1591 \\
23.0488 \\
23.9948\end{array}$ \\
\hline $\begin{array}{l}.25 \\
.26 \\
.27 \\
.28 \\
.29 \\
\end{array}$ & $\begin{array}{l}.1098938 \\
.1055282 \\
.1012084 \\
.0969264 \\
.0926748\end{array}$ & $\begin{array}{l}.0258206 \\
.0238382 \\
.0219446 \\
.0201366 \\
.01841116\end{array}$ & $\begin{array}{l}1.673648 \\
2.00316 \\
2.32924 \\
2.65250 \\
2.97352\end{array}$ & $\begin{array}{l}.75 \\
.76 \\
.77 \\
.78 \\
.79\end{array}$ & $\begin{array}{l}-.1926744 \\
-.206299 \\
-.220901 \\
-.236610 \\
-.253578\end{array}$ & $\begin{array}{l}.0535219 \\
.0599190 \\
.0669937 \\
.0748334 \\
.0835418\end{array}$ & $\begin{array}{l}25.0038 \\
26.0833 \\
27.2424 \\
28.4918 \\
29.8439\end{array}$ \\
\hline $\begin{array}{l}.30 \\
.31 \\
.32 \\
.33 \\
.34\end{array}$ & $\begin{array}{l}.0884466 \\
.0842354 \\
.0800348 \\
.0758391 \\
.0716426\end{array}$ & $\begin{array}{l}.01676613 \\
.01519954 \\
.01370985 \\
.01229585 \\
.01095665\end{array}$ & $\begin{array}{l}3.29283 \\
3.61092 \\
3.92829 \\
4.24537 \\
4.56262\end{array}$ & $\begin{array}{l}.80 \\
.81 \\
.82 \\
.83 \\
.84\end{array}$ & $\begin{array}{l}-.271990 \\
-.292065 \\
-.314074 \\
-.338347 \\
-.365296\end{array}$ & $\begin{array}{l}.0932430 \\
.1040868 \\
.1162557 \\
.1299744 \\
.1455227\end{array}$ & $\begin{array}{l}31.3139 \\
32.9200 \\
34.6842 \\
36.6339 \\
38.8030\end{array}$ \\
\hline $\begin{array}{l}.35 \\
.36 \\
.37 \\
.38 \\
.39\end{array}$ & $\begin{array}{l}.0674398 \\
.0632252 \\
.0589937 \\
.0547400 \\
.0504589\end{array}$ & $\begin{array}{l}.00969164 \\
.00850050 \\
.00738318 \\
.00633986 \\
.00537098\end{array}$ & $\begin{array}{l}4.88046 \\
5.19930 \\
5.51956 \\
5.84165 \\
6.16596\end{array}$ & $\begin{array}{l}.85 \\
.86 \\
.87 \\
.88 \\
.89\end{array}$ & $\begin{array}{l}-.395443 \\
-.429454 \\
-.468197 \\
-.512828 \\
-.564915\end{array}$ & $\begin{array}{l}.1632539 \\
.1836207 \\
.207213 \\
.234815 \\
.267491\end{array}$ & $\begin{array}{l}41.2345 \\
43.9833 \\
47.1212 \\
50.7436 \\
54.9800\end{array}$ \\
\hline $\begin{array}{l}.40 \\
.41 \\
.42 \\
.43 \\
.44\end{array}$ & $\begin{array}{l}.0461453 \\
.0417938 \\
.0373993 \\
.0329561 \\
.0284588\end{array}$ & $\begin{array}{l}.00447722 \\
.00365951 \\
.00291902 \\
.00225716 \\
.001675592\end{array}$ & $\begin{array}{l}6.49292 \\
6.82293 \\
7.15642 \\
7.49380 \\
7.83553\end{array}$ & $\begin{array}{l}.90 \\
.91 \\
.92 \\
.93 \\
.94\end{array}$ & $\begin{array}{r}-.626646 \\
-.701169 \\
-.793190 \\
-.910079 \\
-1.064072\end{array}$ & $\begin{array}{r}.306728 \\
.354663 \\
-.414495 \\
.491227 \\
.593171\end{array}$ & $\begin{array}{l}60.0115 \\
66.0987 \\
73.6312 \\
83.2197 \\
95.8789\end{array}$ \\
\hline $\begin{array}{l}.45 \\
.46 \\
.47 \\
.48 \\
.49\end{array}$ & $\begin{array}{l}.0239016 \\
.01927865 \\
.01458362 \\
.00981010 \\
.00495128\end{array}$ & $\begin{array}{l}.001176243 \\
.000761311 \\
.000433277 \\
.000194922 \\
.000049349\end{array}$ & \begin{tabular}{|ll} 
& 8.18206 \\
& 8.53386 \\
& 8.89143 \\
6 & 9.25528 \\
6 & 9.62595
\end{tabular} & $\begin{array}{l}.95 \\
.96 \\
.97 \\
.98 \\
.99\end{array}$ & $\begin{array}{l}-1.277112 \\
-1.592926 \\
-2.11315 \\
-3.14154 \\
-6.19036\end{array}$ & $\begin{array}{l}.735232 \\
.947112 \\
1.297850 \\
1.993762 \\
4.06209\end{array}$ & $\begin{array}{l}113.4294 \\
139.5018 \\
182.5406 \\
267.798 \\
521.097\end{array}$ \\
\hline .50 & 0 & 0 & 10.00402 & 1.00 & $-\infty$ & $\infty$ & $\infty$ \\
\hline
\end{tabular}


TABLE 3.-Stress coefficients for lateral bending of conical discs, $\sigma=.30$.

\begin{tabular}{|c|c|c|c|c|c|c|c|}
\hline$r / R$ & $p_{1}$ & $-p_{2}$ & $p_{3}$ & $r / R$ & $p_{1}$ & $-p_{2}$ & $p_{3}$ \\
\hline $\begin{array}{l}.00 \\
.01 \\
.02 \\
.03 \\
.04\end{array}$ & $\begin{array}{r}-\infty \\
-412.069 \\
-100.8399 \\
-43.7956 \\
-24.0284\end{array}$ & $\begin{array}{c}\infty \\
280.244 \\
68.8436 \\
30.1006 \\
16.67837\end{array}$ & $\begin{array}{c}\infty \\
31209.9 \\
7638.76 \\
3318.31 \\
1821.085\end{array}$ & $\begin{array}{l}.50 \\
.51 \\
.52 \\
.53 \\
.54\end{array}$ & $\begin{array}{l}.650000 \\
.676528 \\
.704200 \\
.733152 \\
.763534\end{array}$ & $\begin{array}{l}.500000 \\
.513539 \\
.528194 \\
.544032 \\
.561125\end{array}$ & $\begin{array}{l}-51.4753 \\
-53.6293 \\
-55.8788 \\
-58.2347 \\
-60.7094\end{array}$ \\
\hline $\begin{array}{l}.05 \\
.06 \\
.07 \\
.08 \\
.09\end{array}$ & $\begin{array}{r}-14.96886 \\
-10.09557 \\
-7.18545 \\
-5.31459 \\
-4.04388\end{array}$ & $\begin{array}{r}10.52962 \\
7.22454 \\
5.25310 \\
3.98776 \\
3.13023\end{array}$ & $\begin{array}{r}1134.831 \\
765.640 \\
545.144 \\
403.367 \\
307.050\end{array}$ & $\begin{array}{l}.55 \\
.56 \\
.57 \\
.58 \\
.59\end{array}$ & $\begin{array}{l}.795506 \\
.829243 \\
.864938 \\
.902803 \\
.943074\end{array}$ & $\begin{array}{l}.579561 \\
.599438 \\
.620867 \\
.643975 \\
.668906\end{array}$ & $\begin{array}{l}-63.3159 \\
-66.0685 \\
-68.9831 \\
-72.0770 \\
-75.3697\end{array}$ \\
\hline $\begin{array}{l}.10 \\
.11 \\
.12 \\
.13 \\
.14\end{array}$ & $\begin{array}{l}-3.14316 \\
-2.48255 \\
-1.984277 \\
-1.599538 \\
-1.296465\end{array}$ & $\begin{array}{l}2.52420 \\
2.08145 \\
1.749150 \\
1.494168 \\
1.294864\end{array}$ & $\begin{array}{r}238.760 \\
188.6601 \\
150.8584 \\
121.6581 \\
98.6451\end{array}$ & $\begin{array}{l}.60 \\
.61 \\
.62 \\
.63 \\
.64\end{array}$ & $\begin{array}{r}.986012 \\
1.031911 \\
1.081101 \\
1.133955 \\
1.190896\end{array}$ & $\begin{array}{l}.695824 \\
.724915 \\
.756391 \\
.790495 \\
.827503\end{array}$ & $\begin{array}{l}-77.8828 \\
-82.6402 \\
-86.6694 \\
-91.0010 \\
-95.6698\end{array}$ \\
\hline $\begin{array}{l}.15 \\
.16 \\
.17 \\
.18 \\
.19\end{array}$ & $\begin{array}{r}-1.053553 \\
-.855874 \\
-.692812 \\
-.556649 \\
-.441674\end{array}$ & $\begin{array}{r}1.136640 \\
1.009365 \\
.905838 \\
.820830 \\
.750472\end{array}$ & $\begin{array}{l}80.1902 \\
65.1626 \\
52.7577 \\
42.3909 \\
33.6293\end{array}$ & $\begin{array}{l}.65 \\
.66 \\
.67 \\
.68 \\
.69\end{array}$ & $\begin{array}{l}1.252404 \\
1.319031 \\
1.391409 \\
1.470270 \\
1.556461\end{array}$ & $\begin{array}{r}.867734 \\
.911553 \\
.959381 \\
1.011709 \\
1.069105\end{array}$ & $\begin{array}{l}-100.7157 \\
-106.1840 \\
-112.1271 \\
-118.6053 \\
-125.6887\end{array}$ \\
\hline $\begin{array}{l}.20 \\
.21 \\
.22 \\
.23 \\
.24\end{array}$ & $\begin{array}{l}-.343586 \\
-.259098 \\
-.1856618 \\
-.1212805 \\
-.0643692\end{array}$ & $\begin{array}{l}.691855 \\
.642759 \\
.601468 \\
.566640 \\
.537215\end{array}$ & $\begin{array}{r}26.1469 \\
19.69457 \\
14.07923 \\
9.14940 \\
4.78487\end{array}$ & $\begin{array}{l}.70 \\
.71 \\
.72 \\
.73 \\
.74\end{array}$ & $\begin{array}{l}1.650971 \\
1.754958 \\
1.869789 \\
1.997083 \\
2.13878\end{array}$ & $\begin{array}{l}1.132236 \\
1.201882 \\
1.278967 \\
1.364585 \\
1.460047\end{array}$ & $\begin{array}{l}-133.4592 \\
-142.0124 \\
-151.4616 \\
-161.9406 \\
-173.6096\end{array}$ \\
\hline $\begin{array}{l}.25 \\
.26 \\
.27 \\
.28 \\
.29\end{array}$ & $\begin{array}{r}-.01365723 \\
.0318840 \\
.0730951 \\
.1106690 \\
.1451814\end{array}$ & $\begin{array}{l}.512346 \\
.491353 \\
.473684 \\
.458889 \\
.446599\end{array}$ & $\begin{array}{r}.889247 \\
-2.61552 \\
-5.79325 \\
-8.69658 \\
-11.36928\end{array}$ & $\begin{array}{l}.75 \\
.76 \\
.77 \\
.78 \\
.79\end{array}$ & $\begin{array}{l}2.29719 \\
2.47513 \\
2.67604 \\
2.90412 \\
3.16461\end{array}$ & $\begin{array}{l}1.566925 \\
1.687126 \\
1.822974 \\
1.977330 \\
2.15375\end{array}$ & $\begin{array}{l}-186.6610 \\
-201.327 \\
-217.893 \\
-236.707 \\
-258.203\end{array}$ \\
\hline $\begin{array}{l}.30 \\
.31 \\
.32 \\
.33 \\
.34\end{array}$ & $\begin{array}{l}.1771155 \\
.206879 \\
.234821 \\
.261238 \\
.286390\end{array}$ & $\begin{array}{l}.436510 \\
.428369 \\
.421968 \\
.417132 \\
.413718\end{array}$ & $\begin{array}{l}-13.84808 \\
-16.16404 \\
-18.34365 \\
-20.4097 \\
-22.3820\end{array}$ & $\begin{array}{l}.80 \\
.81 \\
.82 \\
.83 \\
.84\end{array}$ & $\begin{array}{l}3.46408 \\
3.81084 \\
4.21558 \\
4.69218 \\
5.25895\end{array}$ & $\begin{array}{l}2.35669 \\
2.59179 \\
2.86631 \\
3.18967 \\
3.57432\end{array}$ & $\begin{array}{l}-282.926 \\
-311.566 \\
-345.007 \\
-384.402 \\
-431.270\end{array}$ \\
\hline $\begin{array}{l}.35 \\
.36 \\
.37 \\
.38 \\
.39\end{array}$ & $\begin{array}{l}.310503 \\
.333776 \\
.356387 \\
.378496 \\
.400248\end{array}$ & $\begin{array}{l}.411605 \\
.410694 \\
.410903 \\
.412167 \\
.414431 \\
\end{array}$ & $\begin{array}{l}-24.2778 \\
-26.1125 \\
-27.8996 \\
-29.6516 \\
-31.3796\end{array}$ & $\begin{array}{l}.85 \\
.86 \\
.87 \\
.88 \\
.89\end{array}$ & $\begin{array}{r}5.94048 \\
6.77038 \\
7.79558 \\
9.08323 \\
10.73220\end{array}$ & $\begin{array}{l}4.03696 \\
4.60040 \\
5.29653 \\
6.17096 \\
7.29083\end{array}$ & $\begin{array}{l}-487.652 \\
-556.337 \\
-641.223 \\
-747.885 \\
-884.537\end{array}$ \\
\hline $\begin{array}{l}.40 \\
.41 \\
.42 \\
.43 \\
.44\end{array}$ & $\begin{array}{l}.421777 \\
.443208 \\
.464658 \\
.486239 \\
.508060\end{array}$ & $\begin{array}{l}.417655 \\
.421806 \\
.426865 \\
.432816 \\
.439656\end{array}$ & $\begin{array}{l}-33.0941 \\
-34.8048 \\
-36.5208 \\
-38.2510 \\
-40.0040\end{array}$ & $\begin{array}{l}.90 \\
.91 \\
.92 \\
.93 \\
.94\end{array}$ & $\begin{array}{l}12.89286 \\
15.80318 \\
19.85801 \\
25.7521 \\
34.8021\end{array}$ & $\begin{array}{r}8.75831 \\
10.73501 \\
13.48915 \\
17.49263 \\
23.6398\end{array}$ & $\begin{array}{l}-1063.672 \\
-1305.066 \\
-1641.541 \\
-2130.86 \\
-2882.53\end{array}$ \\
\hline $\begin{array}{l}.45 \\
.46 \\
.47 \\
.48 \\
.49\end{array}$ & $\begin{array}{l}.530227 \\
.552846 \\
.576023 \\
.599866 \\
.624487\end{array}$ & $\begin{array}{l}.447386 \\
.456017 \\
.465566 \\
.476057 \\
.487522\end{array}$ & $\begin{array}{l}-41.7881 \\
-43.6117 \\
-45.4835 \\
-47.4119 \\
-49.4061\end{array}$ & $\begin{array}{l}.95 \\
.96 \\
.97 \\
.98 \\
.99\end{array}$ & $\begin{array}{r}49.7595 \\
77.1990 \\
136.2744 \\
304.461 \\
1209.305\end{array}$ & $\begin{array}{c}33.7997 \\
52.4381 \\
92.5655 \\
206.807 \\
821.430\end{array}$ & $\begin{array}{r}-4125.41 \\
-6406.56 \\
-11320.03 \\
-25315.3 \\
-100647.9\end{array}$ \\
\hline .50 & .650000 & .500000 & -51.4753 & 1.00 & $\infty$ & $\infty$ & $-\infty$ \\
\hline
\end{tabular}


TABLE 4.-Stress coefficients for lateral bending of conical discs, $\sigma=.30$.

\begin{tabular}{|c|c|c|c|c|c|c|c|}
\hline$r / R$ & $q_{1}$ & $q_{2}$ & $-q_{3}$ & $r / R$ & $q_{1}$ & $q_{2}$ & $-q_{8}$ \\
\hline $\begin{array}{l}.00 \\
.01 \\
.02 \\
.03 \\
.04\end{array}$ & $\begin{array}{c}\infty \\
428.863 \\
109.4320 \\
49.6545 \\
28.5222\end{array}$ & $\begin{array}{c}\infty \\
290.968 \\
73.9901 \\
33.3836 \\
19.02706\end{array}$ & $\begin{array}{c}\infty \\
32477.1 \\
8285.68 \\
3758.74 \\
2158.48\end{array}$ & $\begin{array}{l}.50 \\
.51 \\
.52 \\
.53 \\
.54\end{array}$ & $\begin{array}{l}.650000 \\
.649206 \\
.649426 \\
.650664 \\
.652935\end{array}$ & $\begin{array}{l}-.1500000 \\
=.1629858 \\
=.1759765 \\
=.1890247 \\
-.202182\end{array}$ & $\begin{array}{l}50.2020 \\
50.2128 \\
50.3035 \\
50.4748 \\
50.7282\end{array}$ \\
\hline $\begin{array}{l}.05 \\
.06 \\
.07 \\
.08 \\
.09\end{array}$ & $\begin{array}{r}18.64509 \\
13.22822 \\
9.93124 \\
7.77158 \\
6.27752 \\
\end{array}$ & $\begin{array}{r}12.31570 \\
8.63391 \\
6.39200 \\
4.92257 \\
3.90518\end{array}$ & $\begin{array}{r}1410.590 \\
1000.466 \\
750.873 \\
587.402 \\
474.331\end{array}$ & $\begin{array}{l}.55 \\
.56 \\
.57 \\
.58 \\
.59\end{array}$ & $\begin{array}{l}.656258 \\
.660662 \\
.666186 \\
.672875 \\
.680785\end{array}$ & $\begin{array}{l}-.215504 \\
-.229044 \\
-.242863 \\
-.257023 \\
-.271589\end{array}$ & $\begin{array}{l}51.0654 \\
51.4891 \\
52.0026 \\
52.6097 \\
53.3154\end{array}$ \\
\hline $\begin{array}{l}.10 \\
.11 \\
.12 \\
.13 \\
.14\end{array}$ & $\begin{array}{l}5.19936 \\
4.39477 \\
3.77767 \\
3.29352 \\
2.90636\end{array}$ & $\begin{array}{l}3.17022 \\
2.62101 \\
2.19909 \\
1.867385 \\
1.601472\end{array}$ & $\begin{array}{l}392.751 \\
331.883 \\
285.210 \\
248.602 \\
219.336\end{array}$ & $\begin{array}{l}.60 \\
.61 \\
.62 \\
.63 \\
.64\end{array}$ & $\begin{array}{l}.689984 \\
.700553 \\
.712583 \\
.726185 \\
.741486\end{array}$ & $\begin{array}{l}-.286635 \\
-.302237 \\
-.318481 \\
-.335463 \\
-.353287\end{array}$ & $\begin{array}{l}54.1253 \\
55.0462 \\
56.0859 \\
57.2535 \\
58.5598\end{array}$ \\
\hline $\begin{array}{l}.15 \\
.16 \\
.17 \\
.18 \\
.19 \\
\end{array}$ & $\begin{array}{l}2.59166 \\
2.33225 \\
2.11579 \\
1.933233 \\
1.777816 \\
\end{array}$ & $\begin{array}{r}1.384697 \\
1.205387 \\
1.055157 \\
.927856 \\
.818885\end{array}$ & $\begin{array}{l}195.5559 \\
175.9608 \\
159.6167 \\
145.8386 \\
134.1146\end{array}$ & $\begin{array}{l}.65 \\
.66 \\
.67 \\
.68 \\
.69\end{array}$ & $\begin{array}{l}.758634 \\
.777800 \\
.799185 \\
.823021 \\
.849583\end{array}$ & $\begin{array}{l}-.372072 \\
-.391950 \\
=.413074 \\
-.435615 \\
-.459771\end{array}$ & $\begin{array}{l}60.0169 \\
61.6393 \\
63.4435 \\
65.4490 \\
67.6783\end{array}$ \\
\hline $\begin{array}{l}.20 \\
.21 \\
.22 \\
.23 \\
.24\end{array}$ & $\begin{array}{l}1.644399 \\
1.529018 \\
1.428577 \\
1.340629 \\
1.263215\end{array}$ & $\begin{array}{l}.724748 \\
.642750 \\
.570780 \\
.507172 \\
.450588\end{array}$ & $\begin{array}{r}124.0556 \\
115.3617 \\
107.7985 \\
101.1808 \\
95.3605\end{array}$ & $\begin{array}{l}.70 \\
.71 \\
.72 \\
.73 \\
.74\end{array}$ & $\begin{array}{r}.879189 \\
.912216 \\
.949106 \\
.990389 \\
1.036693\end{array}$ & $\begin{array}{r}-.485773 \\
-.513887 \\
-.544425 \\
-.577756 \\
-.614316\end{array}$ & $\begin{array}{l}70.1581 \\
72.9195 \\
75.9993 \\
79.4413 \\
83.2977\end{array}$ \\
\hline $\begin{array}{l}.25 \\
.26 \\
.27 \\
.28 \\
.29 \\
\end{array}$ & $\begin{array}{r}1.194757 \\
1.133967 \\
1.079790 \\
1.031351 \\
.987924 \\
\end{array}$ & $\begin{array}{l}.399950 \\
.354377 \\
.313145 \\
.275652 \\
.241396\end{array}$ & $\begin{array}{l}90.2181 \\
85.6563 \\
81.5951 \\
77.9685 \\
74.7215\end{array}$ & $\begin{array}{l}.75 \\
.76 \\
.77 \\
.78 \\
.79\end{array}$ & $\begin{array}{l}1.088774 \\
1.147548 \\
1.214126 \\
1.289876 \\
1.376492\end{array}$ & $\begin{array}{l}-.654629 \\
-.699322 \\
-.749161 \\
-.805081 \\
-.868241\end{array}$ & $\begin{array}{r}87.6312 \\
92.5176 \\
98.0492 \\
104.3394 \\
111.5287\end{array}$ \\
\hline $\begin{array}{l}.30 \\
.31 \\
.32 \\
.33 \\
.34\end{array}$ & $\begin{array}{l}.948897 \\
.913757 \\
.882070 \\
.853463 \\
.827622\end{array}$ & $\begin{array}{l}.209953 \\
.1809649 \\
.1541266 \\
.1291751 \\
.1058843\end{array}$ & $\begin{array}{l}71.8079 \\
69.1890 \\
66.8319 \\
64.7086 \\
62.7951\end{array}$ & $\begin{array}{l}.80 \\
.81 \\
.82 \\
.83 \\
.84\end{array}$ & $\begin{array}{l}1.476092 \\
1.591352 \\
1.725701 \\
1.883578 \\
2.07083\end{array}$ & $\begin{array}{r}-.940082 \\
-1.022432 \\
-1.117624 \\
-1.228709 \\
-1.359573\end{array}$ & $\begin{array}{l}119.7926 \\
129.3533 \\
140.4952 \\
153.5868 \\
169.1134\end{array}$ \\
\hline $\begin{array}{l}.35 \\
.36 \\
.37 \\
.38 \\
.39 \\
\end{array}$ & $\begin{array}{l}.804274 \\
.783186 \\
.764157 \\
.747014 \\
.731606 \\
\end{array}$ & $\begin{array}{l}.0840574 \\
.0635226 \\
.0441290 \\
.0257434 \\
.00824728 \\
\end{array}$ & $\begin{array}{l}61.0712 \\
59.5192 \\
58.1239 \\
56.8723 \\
55.7532\end{array}$ & $\begin{array}{l}.85 \\
.86 \\
.87 \\
.88 \\
.89\end{array}$ & $\begin{array}{l}2.29527 \\
2.56756 \\
2.90251 \\
3.32128 \\
3.85488\end{array}$ & $\begin{array}{l}-1.515621 \\
-1.704062 \\
-1.934972 \\
-2.22272 \\
-2.58838\end{array}$ & $\begin{array}{l}187.7236 \\
210.302 \\
238.080 \\
272.814 \\
317.080\end{array}$ \\
\hline $\begin{array}{l}.40 \\
.41 \\
.42 \\
.43 \\
.44\end{array}$ & $\begin{array}{l}.717805 \\
.705497 \\
.694587 \\
.684992 \\
.676641\end{array}$ & $\begin{array}{l}-.00846535 \\
-.0244898 \\
-.0399126 \\
-.0548125 \\
-.0692620\end{array}$ & $\begin{array}{l}54.7569 \\
53.8749 \\
53.1001 \\
52.4264 \\
51.8486\end{array}$ & $\begin{array}{l}.90 \\
.91 \\
.92 \\
.93 \\
.94\end{array}$ & $\begin{array}{r}4.55034 \\
5.48179 \\
6.77183 \\
8.63538 \\
11.47831\end{array}$ & $\begin{array}{l}-3.06387 \\
-3.69960 \\
-4.57882 \\
-5.84753 \\
-7.78139\end{array}$ & $\begin{array}{l}374.786 \\
452.095 \\
559.197 \\
713.963 \\
950.147\end{array}$ \\
\hline $\begin{array}{l}.45 \\
.46 \\
.47 \\
.48 \\
.49\end{array}$ & $\begin{array}{l}.669475 \\
.663446 \\
.658511 \\
.654640 \\
.651808\end{array}$ & $\begin{array}{l}-.0833284 \\
-.0970743 \\
-.1105590 \\
-.1238390 \\
-.1369684\end{array}$ & $\begin{array}{l}51.3624 \\
50.9640 \\
50.6507 \\
50.4203 \\
50.2710\end{array}$ & $\begin{array}{l}.95 \\
.96 \\
.97 \\
.98 \\
.99\end{array}$ & $\begin{array}{c}16.14551 \\
24.6485 \\
42.8244 \\
94.1889 \\
368.372\end{array}$ & $\begin{array}{c}-10.95435 \\
-16.73272 \\
-29.0814 \\
-63.9738 \\
-250.217\end{array}$ & \begin{tabular}{|c}
1338.035 \\
2045.00 \\
3556.83 \\
7831.14 \\
30658.4
\end{tabular} \\
\hline .50 & .650000 & -.1500000 & 50.2020 & 1.00 & $\infty$ & $-\infty$ & $\infty$ \\
\hline
\end{tabular}

